\title{
An observational study of the use of beclomethasone dipropionate suppositories in the treatment of lower urinary tract inflammation in men
}

Giorgio Bozzini $i^{*}$, Marco Provenzano ${ }^{2}$, Nicolò Buffi ${ }^{3}$, Mauro Seveso ${ }^{1}$, Giovanni Lughezzani ${ }^{3}$, Giorgio Guazzoni ${ }^{2,3}$, Alberto Mandressi $i^{1}$ and Gianluigi Taverna'

\begin{abstract}
Background: Nonbacterial prostatitis, together with chronic pelvic pain syndrome, accounts for $90-95 \%$ of prostatitis cases. Anti-inflammatory medications are commonly used to reduce storage/inflammatory symptoms that can deteriorate quality of life. The purpose of this study was to observe the efficacy and safety of beclomethasone dipropionate rectal suppositories $\left(\right.$ Topster $\left.^{\circledR}\right)$ in inflammations of the lower urinary tract in men.

Methods: Patients underwent diagnostic and therapeutic protocols according to current evidence-based practice. Efficacy assessments: voiding parameters, perineal pain, International Prostate Symptom Score (IPSS), digital rectal examination (DRE). Adverse events and patient compliance were recorded throughout the study.

Results: One hundred eighty patients were enrolled, mean age $52 \pm 14.97$. Most frequent diagnosis: nonbacterial prostatitis (85\%). All patients completed visits 1 and 2. All patients were treated with beclomethasone dipropionate (BDP) suppositories, 136/180 also with Serenoa repens (SR) extract. Antibiotics were rarely required.

162/180 patients presented clinically significant improvements and terminated treatment.

Mean change vs. baseline in voiding frequency: $-3.55 \pm 2.70 \mathrm{n} /$ day in patients taking only BDP and $-3.68 \pm 2.81 \mathrm{n} /$ day in those taking both BDP and SR ( $P<.0001$ in both groups). Uroflowmetry improved significantly; change from baseline $3.26 \pm 5.35 \mathrm{ml} / \mathrm{s}$ in BDP only group and $5.61 \pm 7.32 \mathrm{ml} / \mathrm{s}$ in BDP + SR group ( $P=0.0002$ for BDP, $P<.0001$ for BDP + SR). Urine stream normal in $35 \%$ of patients at visit 1 and $57.22 \%$ of patients at visit 2. Mean change in perineal pain, on $0-10$ VAS, $-0.66 \pm 2.24$ for BDP only group $(P=0.0699)$ and $-1.37 \pm 2.40$ for BDP + SR group $(P<.0001)$. IPSS increased at visit 2. No adverse events were reported.

For all parameters, none of the comparisons between groups was found to be statistically significant.

Conclusion: This study confirmed the drug's good safety profile. We also observed an improvement in the main storage symptoms and clinical findings associated with lower urinary tract inflammation in patients treated with beclomethasone dipropionate suppositories.
\end{abstract}

Keywords: Nonbacterial prostatitis, Beclomethasone dipropionate, Lower urinary tract inflammation

\footnotetext{
*Correspondence: gioboz@yahoo.it

'Departmentt of Urology, Humanitas Mater Domini, Via Gerenzano 2, 1 -

21053 Castellanza, Varese, Italy

Full list of author information is available at the end of the article
} 


\section{Background}

Inflammation of the lower urinary tract, especially of the prostate, commonly affects men of a wide age range, with detrimental repercussions on quality of life [1-3]. Symptoms include pelvic pain and a variable degree of voiding and sexual dysfunction $[4,5]$.

Although prostatitis is historically considered mainly a bacterial disease, its most common form is chronic prostatitis/chronic pelvic pain syndrome, accounting for 90-95\% of prostatitis cases $[1,2,6]$.

Traditional medical therapy for prostatitis is centered on treating infection with antimicrobials, although less than $10 \%$ of prostatitis cases are bacterial, and on alleviating symptoms with NSAIDS, alpha-blockers, 5-AlphaReductase Inhibitors, and phytotherapy $[2,6,7]$.

Currently, corticosteroids are not considered "standard of care" for treating prostatitis. However, in a doubleblinded, randomized, parallel study, 160 patients presenting with chronic nonbacterial prostatitis received prednisone and levofloxacin or levofloxacin and placebo; significant differences between the two groups as well as between pre- and post-treatment $(P<0.01)$ were found for total NIH-CPSI score, pain index, voiding index and quality of life [5]. Currently beclomethasone dipropionate suppositories is a part of the standard practice in the hospital.

Furthermore, new formulations of corticosteroids have been developed to limit systemic activity and reduce corticosteroid adverse events [8-12]. Second-generation oral or rectal corticosteroids such as beclomethasone dipropionate have high topical anti-inflammatory efficacy in the gut and minimal systemic bioavailability due to low absorption and highly efficient first-pass hepatic inactivation $[10,11]$. A systematic review of rectal therapies for distal forms of ulcerative colitis found that a greater percentage of patients receiving 5-aminosalicylic acid or corticosteroid rectal formulations obtained therapeutic benefit after treatment compared with placebo [13]. The overall safety profile of rectal therapies was favorable and treatment with beclomethasone dipropionate did not increase the incidence of steroid-related adverse events $[9,10,12,13]$.

The objectives of this study were to collect safety data and observe the effects of beclomethasone dipropionate (Topster ${ }^{\oplus}$, SOFAR S.p.A., Milan, Italy) rectal suppositories on symptoms associated with lower urinary tract inflammation.

\section{Methods}

This was a prospective, observational, single-center study performed on outpatients referred to a highvolume academic teaching hospital in Italy. The study was approved by the local Ethics Committee and written informed consent was obtained from all patients.
Male patients presenting with storage/inflammatory symptoms of the lower urinary tract (pelvic pain, voiding and sexual dysfunction) were observed as they underwent diagnostic and therapeutic protocols according to clinical practice. Subjects affected by coagulation impairments, cardiovascular or pulmonary comorbidities were excluded from the observation, along with those who had undergone a prostatic biopsy within the previous 14 days.

Semen and urine cultures were performed at baseline to determine if the inflammation was triggered by an infection, and whether an antibiotic was therefore indicated.

The following parameters were assessed at each visit: voiding frequency, uroflowmetry, urine stream, perineal pain, prostate-specific antigen (PSA), International Prostate Symptom Score (IPSS) [14] and digital rectal examination (DRE) (evaluation of prostate size, temperature and consistency).

At visit 1, baseline clinical assessments were performed and therapy was prescribed according to current evidence-based practice $[1,2,15,16]$. Patients were then re-evaluated at visit 2 , after the end of the treatment course.

A patient was considered "responder" to therapy following a clinically significant improvement of the evaluated parameters (i.e. voiding frequency, uroflowmetry, urine stream, perineal pain) and the patient's impression of a good clinical outcome.

\section{Drugs prescribed and rationale}

Beclomethasone dipropionate (BDP) rectal suppositories (3 mg, 1 supp. once a day) were prescribed for the relief of inflammation-related storage symptoms. The duration of treatment varied depending on the patient's conditions: 10-day courses were prescribed to patients with mild symptoms (e.g. perineal pain on a $0-10$ VAS between 4 and 6 , voiding frequency less than 10 times a day) or to those expected not to comply with longer treatment; 20-day courses in other cases (severe symptoms, high compliance expected).

Serenoa repens (SR) $320 \mathrm{mg}$ (1 tab. a day for 60 days) was suggested as adjuvant treatment for voiding and storage symptoms due to prostatic hypertrophy and inflammation. We used the only formulation registered as a drug (and not as a dietary supplement) in Italy (Permixon $320 \mathrm{mg}^{\odot}$ ), as requested by the Ethics committee due to the current Literature evidence. It was not prescribed in patients who had already undergone this treatment with unsatisfactory outcomes.

An antibiotic course was prescribed in case of bacterial infection (positive seminal fluid and/or urine cultures). The specific antibiotic was recommended according to antibiogram results, patient preference regarding route 
of administration and current guidelines for the outpatient treatment of lower urinary tract infections $[15,16]$.

A diet (no alcohol, beer or spicy food) and/or hygiene rules (e.g. avoid cycling/riding, prolonged/interrupted sexual intercourse, constipation/diarrhea) were also recommended.

Safety monitoring consisted in gathering all adverse reactions occurring during the study.

All statistical tables, figures, listings and analyses were produced using SAS ${ }^{\oplus}$ for Windows release 9.4 (64-bit) or later (SAS Institute Inc., Cary, NC, USA). Box plots for IPSS score, uroflowmetry, urination frequency, PSA and perineal pain were produced by visit and by type of therapy (BDP suppositories only for patients in group A, or BDP suppositories plus SR for patients in group B). Differences between visit 2 and baseline were analyzed by means of a paired t-test in case of normal data distribution, or a non-parametric Wilcoxon signed rank sum test otherwise. A two independent samples t-test was performed in order to compare the two treatment groups if the changes vs. baseline were normally distributed. Otherwise, the analogous non-parametric test (Wilcoxon-Mann-Whitney test) was used.

\section{Results}

One hundred eighty patients were enrolled in this study between January and December 2013 and all of them completed both visit 1 and visit 2 . One hundred thirty-six patients were treated with both BDP and SR (Group B), whereas 44 were treated with BDP only (Group A).

Patients averaged 52 years of age (SD 14.9, range 2287 ) and nonbacterial prostatitis was by far the most frequent diagnosis, affecting $89.7 \%$ of patients treated with BDP + SR (Group B) and 70.4\% of those treated with BDP (Group A) (Table 1). The mean duration of symptoms was $2.7 \pm 1.8$ months (range 1-12 months) and the number of previous episodes $1.2 \pm 1.2$ (range 0-6).
Approximately $26 \%$ of patients had undergone previous treatment with antibiotics, of which ciprofloxacin, cefixime and levofloxacin were the most commonly prescribed. Urine and semen cultures at visit 1 were positive in 13 (7.2\%) and 12 (6.6\%) patients respectively.

All 180 patients underwent at least one course of therapy with BDP suppositories. Serenoa repens $320 \mathrm{mg}$ (saw palmetto extract) was prescribed to 136 patients. Antibiotics were prescribed to only one patient (Table 2). The other patients with positive urine or semen cultures were already taking the proper antibiotic prescribed by their general practioner.

At visit 2, all patients reported being compliant with the prescribed therapies and suggestions concerning diet and lifestyle.

Mean time elapsed between visits was $99.6 \pm 38.3$ days (range 27-179 days).

\section{Efficacy results}

One hundred sixty-two of the 180 patients treated with BDP presented clinically significant improvements and terminated treatment. Further therapeutic interventions were required for only 18 patients.

The study evidenced noteworthy improvements in voiding parameters. Considering voiding frequency, the changes from baseline were found to be statistically significant $(P<.0001)$ in both groups $(-3.5 \pm 2.7 \mathrm{n} /$ day in patients taking only BDP suppositories and $-3.6 \pm 2.8 \mathrm{n} /$ day in those taking both BDP and SR), whereas the difference in mean change between the two groups was not $(\mathrm{p}$-value $=0.8560)($ Fig. 1$)$.

Uroflowmetry values also improved considerably, with mean values increasing of $3.26 \pm 5.35 \mathrm{~mL} / \mathrm{s}$ in the Group A and $5.6 \pm 7.3 \mathrm{~mL} / \mathrm{s}$ in the Group B. The difference between the two groups was again not statistically significant $(P=0.0638)$ (Fig. 2$)$.

Uroflowmetry data reported in Table $n^{\circ} 3$ are also matched with voided volume and post voided residual

Table 1 Diagnosis

\begin{tabular}{|c|c|c|c|c|c|c|c|}
\hline & & \multirow{2}{*}{\multicolumn{2}{|c|}{$\begin{array}{l}\text { Total } \\
(N=181)\end{array}$}} & \multicolumn{4}{|c|}{ Treatment } \\
\hline & & & & \multicolumn{2}{|c|}{$\begin{array}{l}\text { Group A } \\
(N=45)\end{array}$} & \multicolumn{2}{|c|}{$\begin{array}{l}\text { Group B } \\
(N=136)\end{array}$} \\
\hline & & N & $\%$ & N & $\%$ & N & $\%$ \\
\hline \multirow[t]{7}{*}{ Diagnosis at Baseline } & Chlamydial Urethritis & 2 & 1.10 & 1 & 2.27 & 1 & 0.74 \\
\hline & Chronic Nonbacterial Prostatitis & 3 & 1.66 & 0 & 0.00 & 3 & 2.21 \\
\hline & Nonbacterial Prostatitis & 154 & 85.08 & 31 & 70.45 & 122 & 89.71 \\
\hline & Nonbacterial Prostatitis (First episode) & 3 & 1.66 & 1 & 2.27 & 2 & 1.47 \\
\hline & Post Endoscopic Resection Urethritis & 11 & 6.08 & 7 & 15.91 & 4 & 2.94 \\
\hline & Results of pyelonephritis & 1 & 0.55 & 0 & 0.00 & 1 & 0.74 \\
\hline & Urethritis & 7 & 3.87 & 4 & 9.09 & 3 & 2.21 \\
\hline
\end{tabular}


Table 2 Prescribed medications

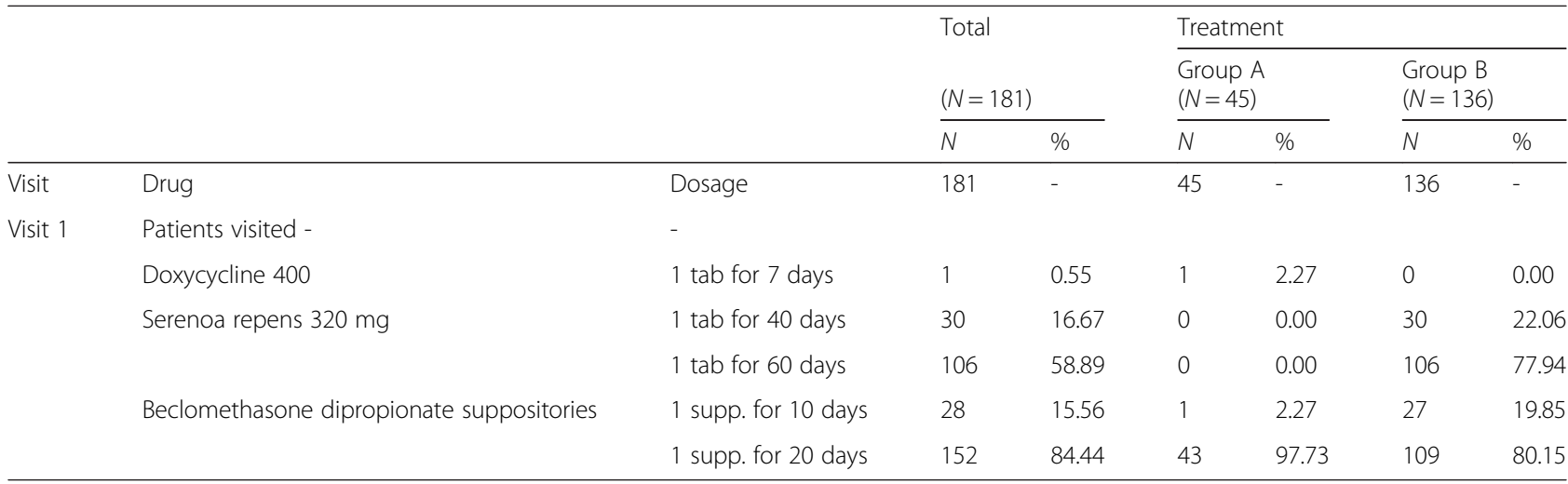

(PVR) to assess the improvements from baseline. The percentage of patients reporting normal urine stream increased significantly, from $43.1 \%$ at baseline to $54.5 \%$ at visit 2 in Group A patients, and from 32.3 to $58.1 \%$ in Group B patients.

At visit 2, patients reported feeling less perineal pain, assessed by means of a Visual Analogue Scale of 0-10. The t-test for the difference between groups was not statistically significant although the p-value (0.0787) suggested a slightly stronger decrease among patients administered both BDP and SR (Fig. 3).

DREs were performed to evaluate prostate volume, temperature and consistency. A clear trend was not apparent for size; an enlarged prostate was detected in
$50.5 \%$ of the patients at visit 1 , and $60.5 \%$ at visit 2 . On the contrary, the number of patients with a warm prostate decreased from $42.7 \%$ of the patients at visit 1 to $5.5 \%$ of the patients at visit 2 . Clinical evidence of an inflamed prostate at DRE was reported in $83.8 \%$ of the patients at visit 1 , whereas $87.7 \%$ of the patients presented a normal prostate at visit 2 .

The mean change from baseline in IPSS was $2.1 \pm 7.9$ $(P=0.0767)$ in Group A patients and $4.7 \pm 7.9(P<.0001)$ in Group B patients, which could suggest a worsening of IPSS score over time, although a temporary rise in score prior to final improvement is quite common in this pathology. The difference in the mean changes from baseline between the two groups was not statistically

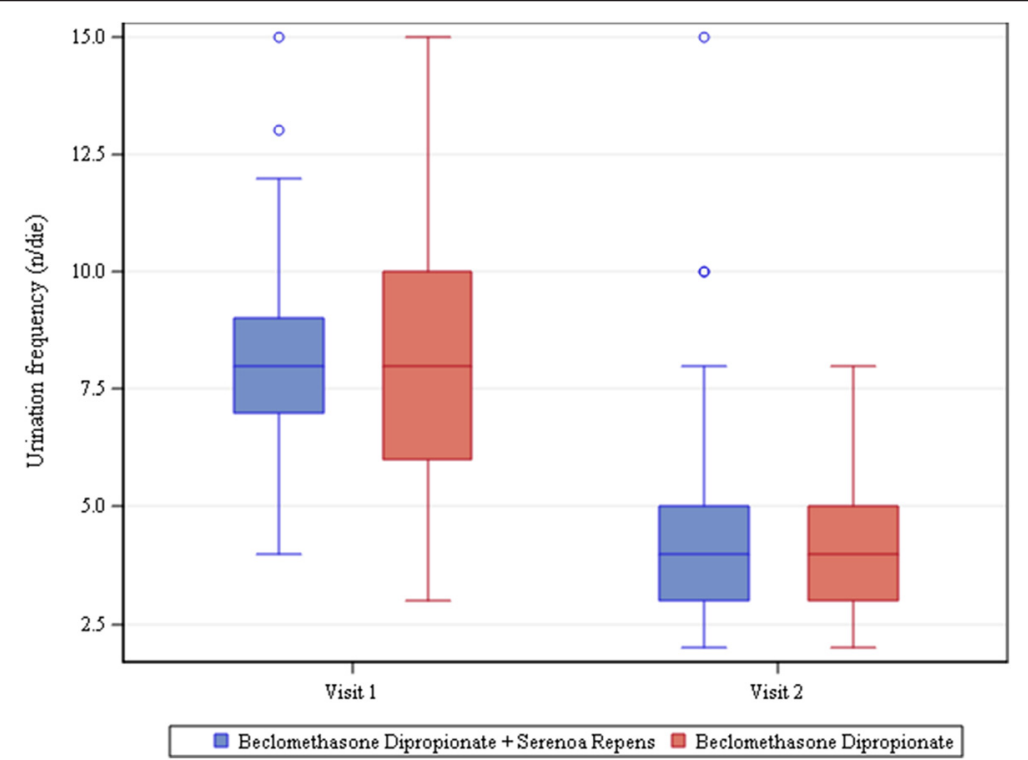

Fig. 1 Voiding frequency. The bottom of each box is the 25th percentile (Q1), the top is the 75th percentile (Q3), and the internal line is the median. The whiskers indicate variability outside the upper and lower quartiles, i.e. scores outside the middle $50 \%$. A circle outside of this range is an outlier, an observation that is distant from others 


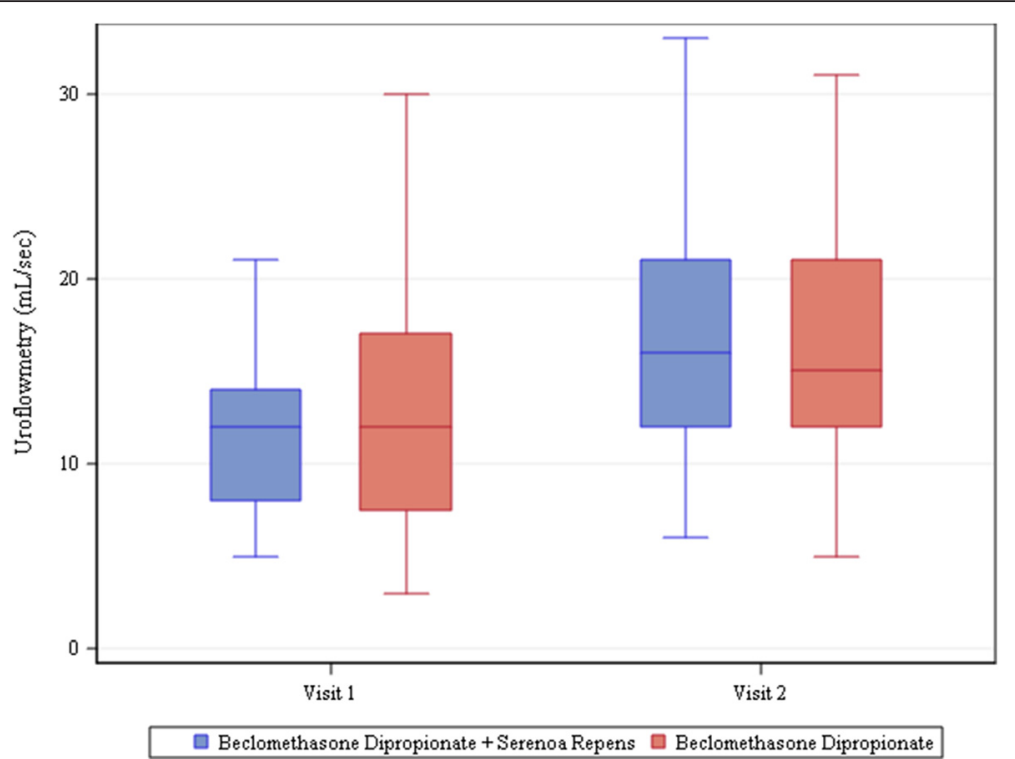

Fig. 2 Uroflowmetry. The bottom of each box is the 25th percentile (Q1), the top is the 75th percentile (Q3), and the internal line is the median. The whiskers indicate variability outside the upper and lower quartiles, i.e. scores outside the middle $50 \%$. A circle outside of this range is an outlier, an observation that is distant from others

significant although a more marked increase of IPSS was present among those patients who took both treatments (Fig. 4).

PSA levels remained stable and below $4.0 \mathrm{ng} / \mathrm{mL}$, dropping slightly from $3.4 \pm 3.2 \mathrm{ng} / \mathrm{mL}$ (range 0.07$21 \mathrm{ng} / \mathrm{mL}$ ) at visit 1 to $3.07 \pm 2.35$ at visit 2 (range 1.10$21.00 \mathrm{ng} / \mathrm{mL}$ ).
Table 3 contains a summary of all the main efficacy results of the study, comparing the two groups of patients.

No adverse reactions or adverse events were reported.

\section{Discussion}

Chronic inflammation plays an important role in the initiation and progression of a wide spectrum of diseases with

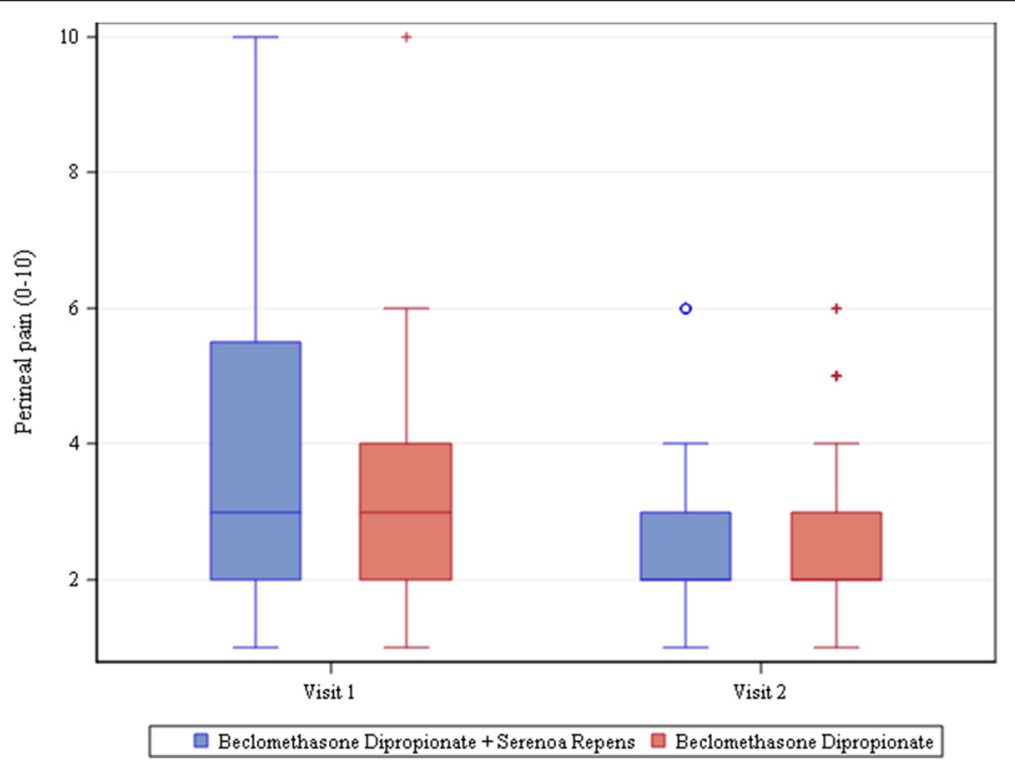

Fig. 3 Perineal pain. The bottom of each box is the 25th percentile (Q1), the top is the 75th percentile (Q3), and the internal line is the median. The whiskers indicate variability outside the upper and lower quartiles, i.e. scores outside the middle $50 \%$. A circle outside of this range is an outlier, an observation that is distant from others 


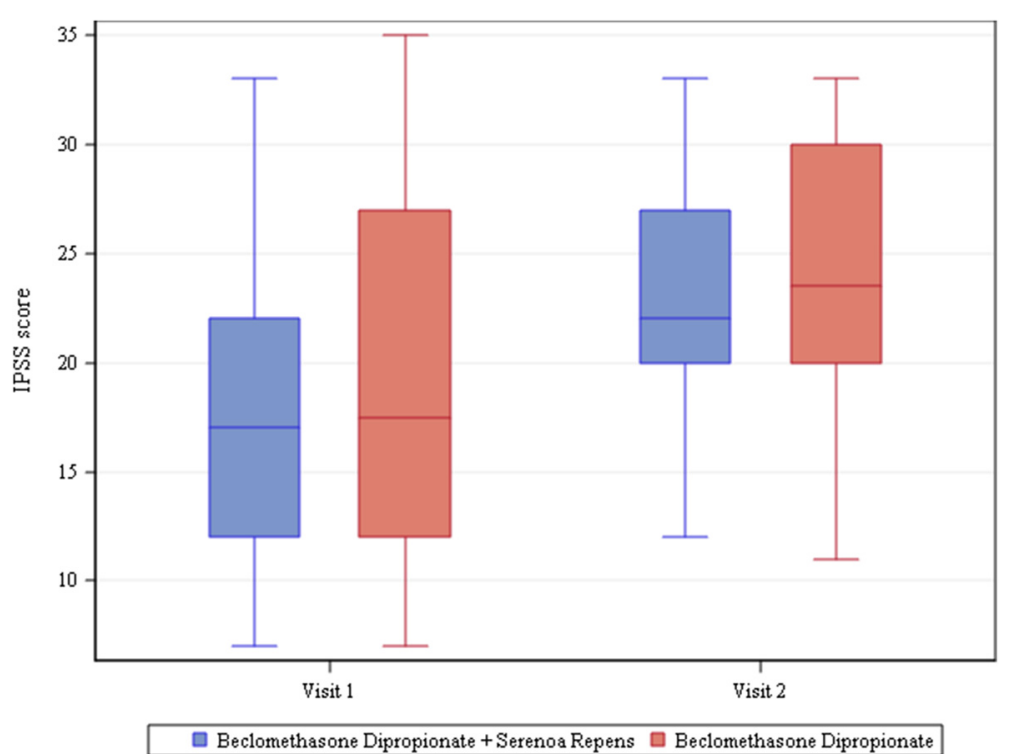

Fig. 4 IPSS score. The bottom of each box is the 25th percentile (Q1), the top is the 75th percentile (Q3), and the internal line is the median. The whiskers indicate variability outside the upper and lower quartiles, i.e. scores outside the middle $50 \%$. A circle outside of this range is an outlier, an observation that is distant from others

prostate involvement [17]. Therefore, anti-inflammatory medications are commonly used in clinical practice for the treatment of several prostatic diseases, including nonbacterial prostatitis. These therapies aim principally at reducing symptoms caused by inflammation (e.g. pelvic pain, voiding dysfunction) that can significantly impair a patient's quality of life $[1,5,6]$.

The vast majority of our patients presenting with lower urinary tract inflammation were affected with nonbacterial prostatitis (85\%). This was an expected result given the high prevalence of this pathological condition $[2,6,7]$. In fact, nearly $50 \%$ of all men experience prostatitis-like symptoms at least once during their lifetime and $90 \%$ of those have abacterial prostatitis $[2,6,7]$.

The majority of patients (152/180) underwent a 20 day course of therapy with BDP suppositories because of the severity of symptoms and the high compliance expected.

Treatment with Serenoa repens is very common and is driven by evidence-based practice to treat voiding and mainly storage symptoms of the lower urinary tract [18-20]. Its widespread use in clinical practice for the treatment of voiding symptoms is also described in several studies [21, 22]. Its beneficial effects are linked mainly to its pro-apoptotic and anti-proliferative properties, which are mediated by various mechanisms including inhibition of $5 \alpha$-reductase, competition with dihydrotestosterone for binding to its receptor and inhibition of fibroblast-growth factor.
BDP suppositories were already found to be a safe and well-tolerated medication in previous studies [10, 11]. One-hundred percent treatment compliance and the absence of adverse reactions in our study substantiate its good safety profile also in inflammations of the lower urinary tract.

The vast majority of patients showed a clinically significant improvement of symptoms at visit 2. In fact, voiding parameters (frequency, uroflowmetry and urine stream) and perineal pain significantly improved during the study, likely with a positive effect on patients' quality of life and perception of good clinical outcome.

We were not able to define a clear trend of improvement of the parameters evaluated by DRE because of the non-standardizable nature of the assessment. However, we did observe a tendency toward normalization in temperature and consistency of the prostate. As expected, PSA levels remained stable since it is not a specific parameter for lower urinary tract inflammation.

In our patients, IPSS increased at visit 2. This was however expected as it is a consequence of the way IPSS is intended to be used in common clinical practice [14]. The mean change from baseline was $2.1 \pm 7.9(P=0.0767)$ in patients taking only BDP and $4.7 \pm 7.9(P<.0001)$ in patients also taking SR. This may indicate a worsening of IPSS, especially in patients taking both treatments, although a temporary increase in score prior to final improvement is quite common in inflammations of the lower urinary tract [23]. In fact, IPSS is more accurate for the evaluation of voiding symptoms, whereas BDP is an 
Table 3 Summary table

\begin{tabular}{|c|c|c|}
\hline \multirow[t]{3}{*}{ Variable } & \multicolumn{2}{|l|}{ Treatment } \\
\hline & Group A & Group B \\
\hline & $(N=45)$ & $(N=136)$ \\
\hline Age & $53.3 \pm 15.1$ & $51.8 \pm 14.9$ \\
\hline \multicolumn{3}{|l|}{ IPSS } \\
\hline Baseline value & $21.6 \pm 7.2$ & $18.3 \pm 6.4$ \\
\hline Value at visit 2 & $23.7 \pm 6.1$ & $23.1 \pm 5.7$ \\
\hline Change from baseline & $2.1 \pm 7.9$ & $4.7 \pm 7.9$ \\
\hline Test of change from baseline & $P=0.0767$ & $P<.0001$ \\
\hline $\begin{array}{l}\text { Change vs baseline }- \text { test between } \\
\text { two groups Two-Sample T-Test }\end{array}$ & $P=0.0593$ & \\
\hline \multicolumn{3}{|l|}{ Voiding frequency (n/day) } \\
\hline Baseline value & $7.7 \pm 2.5$ & $7.8 \pm 2.1$ \\
\hline Value at visit 2 & $4.2 \pm 1.4$ & $4.1 \pm 1.9$ \\
\hline Change from baseline & $-3.5 \pm 2.7$ & $-3.6 \pm 2.8$ \\
\hline Test of change from baseline & $P<.0001$ & $P<.0001$ \\
\hline $\begin{array}{l}\text { Change vs baseline - test between } \\
\text { two groups Two-Sample T-Test }\end{array}$ & $P=0.8560$ & \\
\hline \multicolumn{3}{|l|}{ Uroflowmetry (ml/s) } \\
\hline Baseline value & $13.1 \pm 6.5$ & $11.6 \pm 3.8$ \\
\hline Value at visit 2 & $16.4 \pm 6.7$ & $17.2 \pm 6.5$ \\
\hline Change from baseline & $3.2 \pm 5.3$ & $5.6 \pm 7.3$ \\
\hline Test of change from baseline & $P=0.0002$ & $P<.0001$ \\
\hline $\begin{array}{l}\text { Change vs baseline - test between } \\
\text { two groups Two-Sample T-Test }\end{array}$ & $P=0.0638$ & \\
\hline \multicolumn{3}{|c|}{ Voided volume and post voided residual PVR (ml) } \\
\hline Baseline value & $\begin{array}{l}98.7 \pm 20.5 \\
45 \pm 9.7\end{array}$ & $\begin{array}{l}112.7 \pm 19.3 \\
51 \pm 9.3\end{array}$ \\
\hline Value at visit 2 & $\begin{array}{l}137.3 \pm 33.9 \\
32.4 \pm 9.9\end{array}$ & $\begin{array}{l}139.2 \pm 25.3 \\
30.1 \pm 12.0\end{array}$ \\
\hline Change from baseline & $\begin{array}{l}38.6 \pm 26.3 \\
12.6 \pm 9.1\end{array}$ & $\begin{array}{l}26.5 \pm 23.7 \\
20.9 \pm 11.4\end{array}$ \\
\hline Test of change from baseline & $P=0.0002$ & $P<.0001$ \\
\hline $\begin{array}{l}\text { Change vs baseline - test between } \\
\text { two groups Two-Sample T-Test }\end{array}$ & $P=0.0478$ & \\
\hline \multicolumn{3}{|l|}{ Perineal pain } \\
\hline Baseline value & $3.2 \pm 1.8$ & $3.8 \pm 2.0$ \\
\hline Value at visit 2 & $2.5 \pm 1.2$ & $2.4 \pm 1.1$ \\
\hline Change from baseline & $-0.6 \pm 2.2$ & $-1.3 \pm 2.4$ \\
\hline Test of change from baseline & $P=0.0699$ & $P<.0001$ \\
\hline $\begin{array}{l}\text { Change vs baseline - test between } \\
\text { two groups Two-Sample T-Test }\end{array}$ & $P=0.0787$ & \\
\hline \multicolumn{3}{|l|}{ PSA } \\
\hline Baseline value & $2.8 \pm 2.3$ & $3.6 \pm 3.5$ \\
\hline Value visit 2 & $2.9 \pm 2.1$ & $3.1 \pm 2.4$ \\
\hline Change from baseline & $0.1 \pm 2.5$ & $-0.5 \pm 3.7$ \\
\hline Test of change from baseline & 0.5837 & 0.5036 \\
\hline $\begin{array}{l}\text { Change vs baseline }- \text { test between } \\
\text { two groups Two-Sample T-Test }\end{array}$ & $P=0.3613$ & \\
\hline
\end{tabular}

anti-inflammatory medication and is therefore meant to act mainly on symptoms of the lower urinary tract defined as storage symptoms [24]. Secondly, IPSS echoes the patient's symptoms in the last 4 weeks and does not reflect the 1-day status at visit 2. Therefore, a complete remission of the lower urinary tract inflammation at visit 2 may not be related to an evident improvement in IPSS. Moreover, despite the fact that IPSS is a validated questionnaire, it reflects the patient's feelings and is surely less objective than the other tests performed [25]. As a last comment, we prevented adding bias to this study by not prescribing any alpha-blockers; this choice was made based on the evidence that a lower urinary tract inflammatory disease has to be treated to improve the patients' symptoms [26]. Consequently, IPSS is a tool more suitable for evaluating the long-term outcome of a medical or surgical treatment rather than for the first control after a course of therapy with an anti-inflammatory medication [27].

Given that a significant number of patients took both BDP and SR, we decided to perform a post-hoc analysis in order to exclude any confounding results consequent to the association therapy; none of the comparisons between groups of all the parameters evaluated (voiding frequency, uroflowmetry, perineal pain, IPSS and PSA) were found to be statistically significant. These results confirm the positive effects of BDP suppositories in the treatment of lower urinary tract inflammation. As this is the very first study of its kind, the effectiveness of BDP in lower urinary tract inflammation should be confirmed in a randomized, double-blinded, prospective study.

\section{Conclusion}

Beclomethasone dipropionate proved to be a safe and tolerable drug for treating lower urinary tract inflammations as no adverse events or adverse reactions were reported during the course of the study. All the main parameters (voiding frequency, uroflowmetry, urine stream, perineal pain) improved, except for an increase in IPSS. No significant differences were observed between patients treated with only beclomethasone dipropionate and those also treated with serenoa repens. Although randomized, controlled studies are required to substantiate these findings, our preliminary clinical observations support the use of beclomethasone dipropionate rectal suppositories in male patients affected by lower urinary tract inflammation.

\footnotetext{
Abbreviations

BDP, Beclomethasone dipropionate; DRE, Digital rectal examination; IPSS, International Prostate Symptom Score; PSA, Prostate Specific Antigen; PVR, Post voided residual; SR, Serenoa repens.

Acknowledgements

The authors would like to thank SOFAR S.p.A for their funding of data analysis and the writing of the manuscript.
} 


\section{Funding}

From SOFAR S.p.A for data analysis and the writing of the manuscript.

\section{Availability of data and materials}

All the data supporting our findings will be shared upon request.

\section{Authors' contributions}

GB has made the study design and the critical review. GB, MP, NB and GT have been involved in data interpretation, performed the statistical analysis and drafting the manuscript. GL has been involved in data collection. MS and $A M$ have reviewed the references. GT and GL have been involved in tables drawn. GG and AM have reviewed the manuscript. All authors read and approved the final manuscript

\section{Competing interests}

Dr. Bozzini reports personal fees from SOFAR S.p.A. for data analysis and the writing of this paper. He also reports grants and non-financial support not related to the submitted work. Topster ${ }^{\oplus}$ is also a product of SOFAR

\section{Consent for publication}

Not applicable.

\section{Ethics approval and consent to participate}

The study was approved by the local Ethics Committee (Comitato Etico ASL MI2) and written informed consent was obtained from all patients.

\section{Author details}

'Departmentt of Urology, Humanitas Mater Domini, Via Gerenzano 2, I -

21053 Castellanza, Varese, Italy. ${ }^{2}$ Humanitas University, Milan, Italy.

${ }^{3}$ Department of Urology, Humanitas Research Hospital, Milan, Italy.

Received: 13 September 2015 Accepted: 31 May 2016

Published online: 08 June 2016

\section{References}

1. Rees J, Abrahams M, Doble A, Cooper A. Prostatitis Expert Reference Group (PERG). Diagnosis and treatment of chronic bacterial prostatitis and chronic prostatitis/chronic pelvic pain syndrome: a consensus guideline. BJU Int. 2015 Feb 24; doi:10.1111/bju.13101.

2. Gurunadha Rao Tunuguntla HS, Evans CP. Management of prostatitis. Prostate Cancer and Prostatic Dis. 2002;5(3):172-9.

3. Collins MM, Stafford RS, O'Leary MP, Barry MJ. How common is prostatitis? A national survey of physician visits. J Urol. 1998;159:1224-8.

4. Artibani W, Pesce F, Prezioso D, Scarpa RM, Zattoni F, Tubaro A, Rizzi CA, Santini AM, Simoni L. FLOW study group. Italian validation of the urogenital distress inventory and its application in LUTS patients. Eur Urol. 2006:50(6):1323-9.

5. Bartoletti R, Cai T, Mondaini N, et al. Prevalence, incidence estimation, risk factors and characterization of chronic prostatitis/chronic pelvic pain syndrome in urological hospital outpatients in Italy: results of a multicenter case-control observational study. J Urol. 2007;178(6):2411-5.

6. Wagenlehner Florian ME et al. Prostatitis and Male Pelvic Pain Syndrome. Dtsch Arztebl Int. 2009;106(11):175-83.

7. Öztekin I et al. Therapeutic Effects of Oligonol, Acupuncture, and Quantum Light Therapy in Chronic Nonbacterial Prostatitis. Evid Based Complement Alternat Med. 2015;2015:687196.

8. Yang MG, Zhao XK, Wu ZP, et al. Corticoid combined with an antibiotic for chronic nonbacterial prostatitis. Zhonghua Nan Ke Xue. 2009:15(3):237-40.

9. Talbot M, Bates S. Variability of the symptoms of chronic abacterial prostatitis/ chronic pelvic pain syndrome during intermittent therapy with rectal prednisolone foam for ulcerative colitis. Int J STD AIDS. 2001;12(11):752-3.

10. Fascì Spurio F et al. Low Bioavailability and Traditional Systemic Steroids in IBD: Can the Former Take Over the Latter? Gastrointestin Liver Dis. 2013;22(1):65-71.

11. Campieri M. New steroids and new salicylates in inflammatory bowel disease: a critical appraisal. Gut. 2002;50(Suppl III):iii43-6.

12. Kumana CR, Seaton T, Meghji M, Castelli M, Benson R, Sivakumaran T. Beclomethasone dipropionate enemas for treating inflammatory bowel disease without producing Cushing's syndrome or hypothalamic pituitary adrenal suppression. Lancet. 1982;1(8272):579-83.
13. Cohen RD1, Dalal SR. Systematic Review: Rectal Therapies for the Treatment of Distal Forms of Ulcerative Colitis. Inflamm Bowel Dis. 2015 May 27. [Epub ahead of print].

14. Barry MJ, Fowler Jr FJ, O'Leary MP, Bruskewitz RC, Holtgrewe HL, Mebust WK Cockett AT. The American Urological Association symptom index for benign prostatic hyperplasia. The Measurement Committee of the American Urological Association. Journal of Urology. 1992;148(5):1549-57.

15. Naber KG, Bergman B, Bishop MC, Bjerklund-Johansen TE, Botto H, Lobel B, Jinenez Cruz F, Selvaggi FP. EAU guidelines for the management of urinary and male genital tract infections. Eur Urol. 2001;40(5):576-88.

16. Grabe M, Bartoletti R, Bjerklund Johansen TE, Cai T, Çek M, Köves B, Naber KG, Pickard RS, Tenke P, Wagenlehner F, Wullt B. Guidelines on Urological Infections. http://uroweb.org/guideline/urological-infections/. Accessed 04 Aug 2015

17. Bernichtein $\mathrm{S}$ et al. Anti-Inflammatory properties of Lipidosterolic extract of Serenoa repens (Permixon ${ }^{\oplus}$ ) in a mouse model of prostate hyperplasia. Prostate. 2015;75(7):706-22

18. Debruyne F, Boyle P, Calais Da Silva F, Gillenwater JG, Hamdy FC, Perrin P, Teillac P, Vela-Navarrete R, Raynaud JP, Schulman CC. Evaluation of the clinical benefit of permixon and tamsulosin in severe BPH patients-PERMAL study subset analysis. Eur Urol. 2004;45(6):773-9. discussion 779-80.

19. Debruyne F, Koch G, Boyle P, Da Silva FC, Gillenwater JG, Hamdy FC, Perrin P, Teillac P, Vela-Navarrete R, Raynaud JP. Comparison of a phytotherapeutic agent (Permixon) with an alpha-blocker (Tamsulosin) in the treatment of benign prostatic hyperplasia: a 1-year randomized international study. Eur Urol. 2002:41(5):497-506. discussion 506-7.

20. Latil A, Pétrissans MT, Rouquet J, Robert $G$, de la Taille A. Effects of hexanic extract of serenoa repens (permixon $\left.{ }^{\circledR}\right) 160 \mathrm{mg}$ ) on inflammation biomarkers in the treatment of lower urinary tract symptoms related to benign prostatic hyperplasia. Prostate. 2015;75(16):1857-67.

21. Magri V, Marras E, Restelli A, Wagenlehner FM, Perletti G. Multimodal therapy for category III chronic prostatitis/chronic pelvic pain syndrome in UPOINTS phenotyped patients. Exp Ther Med. 2015:9(3):658-66.

22. Morgia $\mathrm{G}$ et al. Serenoa repens, lycopene and selenium versus tamsulosin for the treatment of LUTS/BPH. An Italian multicenter double-blinded randomized study between single or combination therapy (PROCOMB trial). Prostate. 2014:74(15):1471-80.

23. Lee HN, Kim TH, Lee SJ, Cho WY, Shim BS. Effects of prostatic inflammation on LUTS and alpha blocker treatment outcomes. Int Braz J Urol. 2014:40(3):356-66.

24. Haylen BT, de Ridder D, Freeman RM, Swift SE, Berghmans B, Lee J, Monga A, Petri E, Rizk DE, Sand PK, Schaer GN. IUGA/ICS Joint Report On The Terminology For Female Pelvic Floor Dysfunction: Standardisation and Terminology Committees IUGA and ICS, Joint IUGA/ICS Working Group on Female Terminology. Neurourol Urodyn. 2010:29(1):4-20.

25. Matsukawa Y, Hattori R, Sassa N, Yamamoto T, Gotoh M. What are the factors contributing to failure in improvement of subjective symptoms following silodosin administration in patients with benign prostatic hyperplasia? Investigation using a pressure-flow study. Neurourol Urodyn. 2013;32(3):266-70.

26. Park SG, Chung BH, Lee SW, Park JK, Park K, Cheon J, Lee KS, Kim HJ, Seong DH, Oh SJ, Kim SW, Lee JY, Choo SH, Choi JB. Alpha-blocker treatment response in men with lower urinary tract symptoms based on sympathetic activity: prospective multicenter open-Labeled observational study. Int Neurourol J. 2015;19(2):107-12.

27. Fujimura $T$ et al. Assessment of lower urinary tract symptoms in men by international prostate symptom score and core lower urinary tract symptom score. BJU Int. 2012;109(10):1512-6. 